defective recognition of the position of the object in space, and especially of its distance." The cases show, I think, that the statement would be more complete if after "damage of these portions of the cortex" "there were added, "or of their afferent fibre connections from the retinal end-organs."

The last clause of the paragraph I have quoted seems to indicate that Dr. Holmes assumes there is some other independent cortical centre which has to do with the recognition of the positions of objects in space. This may be so; yet if the potential response of the eye-movements centre is interfered with, either by lesion of the centre itself or of the afferent path associated with that centre, this would surely be enough to account for the symptoms. In cases of oculo-motor paralysis, although projection may be faulty, there is no change in the relative localization of external objects. This is evidently because the voluntary oculo-motor centre with its afferent tract are not involved in the lesion causing the paralysis. The reflex and voluntary innervations are normal, but the response to efferent stimuli is defective. Consequently, projection is no longer in accordance with the position of the eye, as from established habit it normally is.

\title{
JOTTINGS ON LOCAL ANAESTHESIA IN OPHTHALMIC SURGERY*
}

\author{
BY \\ S. JOHNSON TAYLOR, \\ NORWICH.
}

I wAS suddenly summoned by telephone by a Suffolk doctor to go over and see a patient with exophthalmic goitre, whose left eye had become seriously aftected; if I found it necessary to remove it, what preparation for the anaesthetic should I like? I replied I would come and remove the eye if necessary and that no preparation for an anaesthetic was necessary. I went; a glance was sufficient to condemn the globe, and with perfect ease and freedom from pain I proceeded to remove it under local anaesthesia. The doctor concerned, an able man, told me he had thought it necessary to remove the eye during my absence and was prepared to do it ; in fact, he had called in a colleague to give a general anaesthetic for the purpose, but the colleague was so concerned at the patient's condition that he declined to administer any such, and she was left for my return.

A few weeks later I saw for a colleague a woman with a good-

* Read at the Oxford Ophthalmological Congress, July, 1917. 
sized melanotic sarcoma in the ciliary region and removed the globe under local anaesthesia the following evening.

Quite recently, on the couch in my consulting room, I did an iridectomy under local anaesthesia for acute glaucoma of both eyes - not at the same sitting, as the attacks did not synchronize-the patient walked and "trammed" home; and about the same time I did an iridectomy by the same method on a London patient for increased tension with a nearly closed pupil, and on my consulting room couch I excised a lacrymal sac by its aid. These are but a few examples. For ordinary cataract extractions, Elliot's trephining, squint advancements and tenotomies, optical and preliminary iridectomies - the latter of which I am now convinced is in most cases a mistake, for I consider the simple extraction far and away the best one--I find the ordinary instillation of 2 per cent. cocain into the conjunctival sac with a little adrenalin quite sufficient.

I am now quite sure of the boon local anaesthesia is to us all, and especially to anyone situated like myself, and with a fairly large clientèle amongst all sorts and conditions, rich and poor, for I have never held any hospital appointment in the County of Norfolk, and have all along been handicapped in the operative treatment of our poorer brethren. I hold that every medical man, according to his lights, should do what he can for the less well off, and, failing to get an appointment many years ago at the Norwich Eye Infirmary, I had to have recourse to other ways and means and took to seeing out-patients at my own house at an early hour every week-day morning, the result being that I very soon had a large attendance at that time; with this came the difficulty of doing and dealing with the operations necessarily often involved.

Operating on these patients in their own homes presented many difficulties. Some of the furniture required removal, the geraniums had to be cleared away from the window sill and other treasures from the table in the middle of the room. There was generally a couch on the premises, if not in the parlour, in some other room, but it was not always quite handy for the left eye and vice versathe back would stick up in an awkward way; then, in spite of the removal of the geraniums, the light was not always quite nice, and the sun would at times annoyingly set on the wrong side. Moreover, the antiseptic arrangements were not always above suspicion. .

I began to wonder if these cases could not be done at my own house, and gradually took to doing them there, and now for many years I have done excisions, removals of sacs, all sorts of squint operations, cataracts, and iridectomies, etc., five, six, or seven of an afternoon, on my consulting room couch, some of the extractions being simple ones, the patients getting up and walking home a mile or so afterwards, and not once have I had any complication of any kind whatever as a result thereof. Think what a gain that was to me : 
a perfect north light, with the electric light handy in case daylight was insufficient, and all the antiseptic, etc., measures under my own control. But one thing was wanting, viz., the difficulty I had to contend with in excision of an eye and cases of acute and subacute glaucoma, etc., etc., too painful to do as a rule under the ordinary method of local anaesthesia. It was awkward and expensive getting in another medical man to give a general anaesthetic. Sometimes, I admit, I gave it myself and did the operation too, and there was the risk of patients being sick in my room; then they had to be kept an hour or so before I liked to send them home, and frequently the expense of a cab was necessary. So, as I regularlymany years ago-took to excising lacrymal sacs under injections of novocaine cum suprarenin borate, I began to wonder whether the same method could be used for excision of the globe, and one dark winter Sunday afternoon I had a poor fellow who crystallised the business and made me take the plunge, for to me it was quite new ground. I had never seen, heard, or read of a case, and almost fancy the method must have originated in my consulting room that day. It is true I had seen Mr. Couper, at Moorfields, excise eyes by repeated injections of cocain with repeated snips as he went on, but his plan appeared to me cruel and unsatisfactory, and never caught on. This poor chap had an absolutely impossible, dark, dismal, and dirty home up a yard in Norwich, his wife was stone blind of both eyes, and he had an attack of acute glaucoma, which I saw too late, and for which, to try to relieve his pain, I had done an unsuccessful iridectomy under the ordinary local anaesthesia. The eye was acutely congested and inflamed, horribly painful and tender, and about as bad an eye to experiment on as one could wish. I thought I would try to remove it under deep local anaesthesia and injected a solution of novocaine cum suprarenin borate well back towards the apex of the orbit, using a straight needle and going through the upper and lower lid, aiming at the tissues at the back of the eye. Then, after about 25 minutes waiting, I began, going very slowly and cautiously, avoiding any drag on the muscles during their division, and completing the operation without any pain. A firm bandage was applied and the patient walked home, so far as I can recollect-for it is a good many years ago-quite alone. If I could get that eye out painlessly by deep local anaesthesia, I could remove any eye without pain, and ever since I have been removing them in this way, but I soon found out that it was better to go through the conjunctiva with the needle at the inner and outer canthus, and, though for years I used a straight needle, I have recently got Messrs. Weiss to make me a couple of slightly curved and fine needles which I always use now - -you can get round the globe better with them.

The greater includes the less, and I often thought of doing my 
acute and subacute glaucomas in the same way, and probably should have come to this in time, but I was afraid that the needle moving about in an unknown way in the region of the optic and ciliary nerves and blood-vessels might do harm and imperil the result of the operation. It was entirely owing to George Pooley that I took the plunge; all credit is due to him and the paper he read at this Congress some three years ago (Ophthalmoscope, 1914, p. 464).

With his experience added to my own I at once took to this method of anaesthesia in practically all cases needing it or a general anaesthetic, and I very seldom have the latter administered now. There are some points of detail to be mentioned. I used always to inject along the inner and outer side of the eye-I do that still for excision-but for other cases I only inject along the outer rectus, going well back and aiming at about the posterior pole of the eye and thus catching the ciliary nerves and perhaps the lenticular ganglion. About 20 minutes after the injection you can operate.

The globe is somewhat proptosed by the procedure and is quite fixed, the muscles, apparently, being rendered functionless. Another point-which rather upset me in my first case-to be noted is the decided dilatation of the pupil which in glaucoma is not desirable, so in such I use eserin rather liberally to obviate this.

Another point is not to put on a very tight pad and bandage, as striate keratitis-the result of pressure--may be marked if you do. I alway use tabloids of novocain cum suprarenin borate, two for an excision, one for other operations ; each tabloid is dissolved in about a cubic centimetre of boiled and hot water. ${ }^{*}$ I have never used stovain or alypin, etc., and am quite satisfied; the addition of suprarenin makes an operation almost bloodless.

When operating on the lacrymal sac I inject along the line of the skin incision and also a few drops as near the anterior ethmoidal foramen as I can judge, in order to catch the infra-trochlear branch of the nasal branch of the first division of the fifth nerve, which supplies the lacrymal sac. The patients go home quietly and have their usual meals and, if the eyes are secured properly, no harm results. As a first dressing I use a narrow, about $\frac{3}{4}$ of an inch wide, strip of thin silk, antiseptic, salicylic plaster, going from the forehead over the lids and on to the cheek-this they cannot get oft-then a pad of wool, retained in position by a bendage in males and by three strips of Mead's plaster in females.

By this method of local anaesthesia you can do almost every operation on the eye and lids. I have never done an exenteration

*The tabloids made by the Saccharin Corporation, Ltd., contain 0.1 gramme of novocain and 0.00025 of suprarenin borate, and are very convenient ; boiling water and a tablespoon can always be obtained. 
of the orbit by it, but I think I could; in fact, I hardly ever call in the services of a general anaesthetist.

To our old-fashioned notions I know all this seems rather horrible, and many of you will think my plans of procedure and campaign somewhat extreme ; but, as John Hunter said, " don't think, but try."

Is one more liable to get intra-ocular choroidal haemorrhage, etc., by this method? Does the effort and exertion of walking home increase the risk? No, it does not; if anything it tends to reduce it by determining the blood to other parts and muscles called into action by the exercise. The cases of post-operation haemorrhage are due, of course, to a diseased condition of the blood-vessels unable to stand the rush of blood into them, and for the most part the bleeding comes on before the patient is off the table. Mr. Charles Higgens showed, at the Ophthalmological Society a good many years ago, three cases lost by haemorrhage following cataract extraction, and I had one in an only eye following iridectomy for acute glaucoma under a general anaesthetic years ago in a woman by no means a teetotaler.

Look at the advantages of the method: no assistant or nurse required; no preparations for general anaesthesia or vomiting and general disturbance following therefrom; no interference with the diet ; no struggling as the patient " goes under," no coming round of the patient and sudden movement when least expected; no anxiety due to sudden cessation of heart's action or respiration with artificial respiration and the mauvais quart d'heure following. The one little inconvenience is the prick of the needle during the injection; the site thereof is, of course, cocainised, but some slight pain is caused ; occasionally a little faintness is produced, which is relieved by a dose of sal volatile or spirits.

\section{RING INFILTRATION OF THE CORNEA IN A CASE OF PURPURA WITH A DISCUSSION OF ITS PATH- OGENESIS AND SOME GENERAL OBSERVATIONS ON THE DIFFERENT FORMS OF CORNEAL INFILTRATION *}

BY

D. V. Giri, D.O. (Oxon),
Eastbourne.

Foreword

WhATEVER the incidence of ring infiltration or so-called ring abscess of the cornea after operations involving the introduction of

* Paper presented to the Oxford Ophthalmological Congress in July, 1917; written while the Author was Resident Surgeon to the Free Eye Hospital, Southampton. 